\title{
Water Quality Parameters and Fish Biodiversity Indices as Measures of Ecological Degradation: A Case Study in Two Floodplain Lakes of India
}

\author{
Debjit Kumar MONDAL ${ }^{1}$, Anilava KAVIRAJ ${ }^{1}$, Subrata SAHA ${ }^{2}$ \\ ${ }^{1}$ Department of Zoology, University of Kalyani, Kalyani, India \\ ${ }^{2}$ Department of Mathematics, Institute of Engineering and Management, Salt Lake, Kolkata, India \\ E-mail:akaviraj@gmail.com \\ Received October 24, 2009; revised November 16, 2009; accepted November 23, 2009
}

\begin{abstract}
A three year study was conducted in two floodplain lakes to evaluate changes between seasonal variation of water quality parameter and finfish diversity indices. Samples of water and fish specimens were collected every month from three different stations of each lake to determine physico-chemical parameters of water and the finfish diversity indices. Split-plot and MANOVA designs, Multiplicative decomposition method and quadratic regression analysis were used to analyze the effects of the rate of changes between the parameters and sustainability of the lakes. The obtained results suggested that the impact of environmental change (e.g depth, conductivity, salinity of water etc.) on diversity indices was significant and should be taken into consideration when designing policies to increase the long-term sustainability of fishing activities in the lakes.
\end{abstract}

Keywords: Baur, Finfish, Diversity Indices, Multiplicative Decomposition, Quadratic Regression

\section{Introduction}

Floodplain lakes support a lucrative fishery in India, particularly in the eastern and north-eastern states and are considered as the second most important inland fisheries resources of the country [1]. These water bodies are not only rich in finfish biodiversity, but also support a rich source of zooplankton, phytoplankton and macroinvertebrate species [2]. It is well established that the productivity of a water body depends on its ecological conditions. Productivity can be increased for obtaining maximum sustainable yield of fish and maintenance of environmental and social stability through constant monitoring of water quality. The water quality parameters like temperature, hardness, $\mathrm{pH}$, dissolved gases (oxygen and $\mathrm{CO}_{2}$ ), salinity etc. must be watched regularly, individually or synergistically to keep the aquatic habitat favorable for existence of fish.

The present investigation was conducted to study the water quality parameters in two floodplain lakes for a period of three year from 2004 to 2006. In West Bengal, more than 150 floodplain lakes, covering an area of 42,000 ha, contribute about $22 \%$ of the total freshwater area of the state [1]. Largest share of this water resources
(8861 ha) exists in the North 24-Parganas district [3]. River Ichhamati and its branches form a large complex of floodplain lakes, locally called as "baurs", at Bongaon region of North 24-Parganas [4]. Most of these baurs are open with a seasonal or perennial connection with the river Ichhamati and are fed with tidal ingress of saline water from the Bay of Bengal. Thus these baurs show characteristics of both lentic and lotic elements [2]. Many brackish water species of fish migrate from the mouth of this river into the baurs during breeding season and exploit the rich nutrient resources of these water bodies for spawning. We made a study on the fish assemblage, water quality parameters and biodiversity indices of two such baurs. The assemblage of fish and the pattern of changes in the composition and abundance of the fish species in these two floodplain lakes during the period 2004 to 2006 had been already reported [5]. The present paper dealt with changes in physico-chemical parameters of water and its relation with the fish biodiversity indices in these two lakes during the same period.

Fish assemblages in lakes and reservoirs are greatly influenced by water quality parameters [6]. Floodplain lakes in India have become worst victims of environmental degradation since last two decades. Majority of 
these water bodies are shrinking due to siltation caused by high fluvial allochthonous charges from the river meanders, discharge of organic debris from human settlements around the lakes, run-offs from agricultural fields, eutrophication and autochthonous production of macrophytic biomass $[2,7,8]$. Indiscriminate jute retting during summer months and subsequent deterioration of water quality is also a serious threat to the fish biodiversity and productivity of floodplain lakes in West Bengal [9]. Therefore, changes in the water quality parameters and its relation with biodiversity indices are crucial factors to evaluate fish biodiversity in floodplain lakes.

\section{Materials and Methods}

\subsection{Study Area}

Studies were made on two baurs, Gopalnagar and Dumar, located in the Bongaon Subdivision $\left(23.07^{\circ} \mathrm{N} 66.82^{\circ} \mathrm{E}\right)$ in the North 24-Parganas district of West Bengal. These two 'baurs' were found connected to the river Ichamati throughout the year by a narrow canal. The Gopalnagar baur was smaller of the two with a length of $6 \mathrm{~km}$ containing 60 ha water area while the Dumar baur was 15 $\mathrm{km}$ long containing a water area of 395 ha. A map showing location of these two baurs along the course of the river Ichamati had been published in another paper [5].

\subsection{Sampling}

Three different stations were selected in each baur for sampling of fish and water. One station was located near the connection of the baur with the river (mouth), the second in the middle of the baur and the third at far end from the mouth. Samplings were done every month from January 2004 to December 2006.

For water quality analysis random samples of water were collected from three different locations of each station in the morning of the first week of every month during January 2004 to December 2006. Water samples were collected from $50 \mathrm{~cm}$ depth in each collection site. Depth of water, dissolved oxygen (DO), free carbon dioxide, $\mathrm{pH}$, total alkalinity, hardness, salinity, conductivity, transparency and surface water temperature of water were determined using standard methods [10]. A Celsius thermometer (scale ranging from $0^{\circ} \mathrm{C}$ to $100^{\circ} \mathrm{C}$ ) was used to measure surface water temperature of water. $\mathrm{pH}$ of water was measured directly in a digital electronic $\mathrm{pH}$ meter (Systronics) and specific conductivity of water was measured in a digital direct reading electronic conductivity meter (Model 304, Systronics). Transparency was measured with the help of a Secchi disc. Dissolved oxygen (DO), free carbon dioxide, total alkalinity, hardness and salinity were determined by titration [10].

For determination of diversity indices random samples of fish were taken from five nettings from each stations and pooled together to make a $500 \mathrm{~g}$ sample of fish for each station for each month. Total number of species, total number of individuals in a sample and total number of individuals of a species were determined every month. From these data Shannon-Weaver (S-W) species diversity index [11], Evenness index [12] and Index of Dominance [13] were determined using the following equations:

$$
\text { S.W. Species Diversity index } \overline{\mathrm{H}}=-\sum_{i=1}^{s}(\mathrm{~N} i / \mathrm{N}) \log _{2}(\mathrm{~N} i / \mathrm{N})
$$

where $\mathrm{S}$ is the total number of species; $\mathrm{N}$ is the total number of individual; $\mathrm{N} i$ is the number of specimens in each species.

$$
\text { Evenness Index }\left(\mathrm{J}^{\prime}\right)=(\overline{\mathrm{H}}) / \log _{2} \mathrm{~S} \text {. }
$$

where $\bar{H}$ is the S.W. Species Diversity Index; $S$ is the total number of species.

$$
\text { Index of Dominance (ID) }=\sum(\mathrm{N} i / \mathrm{N})^{2}
$$

where $\mathrm{N}$ is the total number of individual; $\mathrm{N} i$ is the number of individuals in each species.

\subsection{Data Analyses}

To determine the relative importance of year compared to age of the baur a mixed-effects analysis of variance (MANOVA and Split-plot) was conducted in which yearly variation was considered a random effect. Significance was determined at alpha $=0.05$. F-ratio obtained from the analyses was tested for significance of difference between stations. Data indicated that there was annual and monthly variation in the various measures of chemical limnology. In case of a significant variation, difference between the stations were compared with critical difference (CD) value for station and the station with greater variance was selected from each year data for further analyses. A trend cycle was estimated for each parameter from the observed data. For this purpose the data series was smoothed to reduce random variation using Multiplicative decomposition technique [14]. In order to make predictions of long term behavior of relation between the water quality parameters and the diversity indices, best fitted parabolic curves were constructed from the three year data based on quadratic regression in the form $\mathrm{Y}=\mathrm{a}+\mathrm{bx}+\mathrm{cx}^{2}$. Physically it was interpreted that, if $\mathrm{a}, \mathrm{b}, \mathrm{c}$ were all greater (positive) an increase in $\mathrm{x}$ would result in increase of $Y$ and if $a, b$, c were all negative then a reverse trend would be followed. Long term growth or decay would follow accordingly as c was positive or negative.

\section{Results}

The results indicated a conspicuous seasonal variation of 

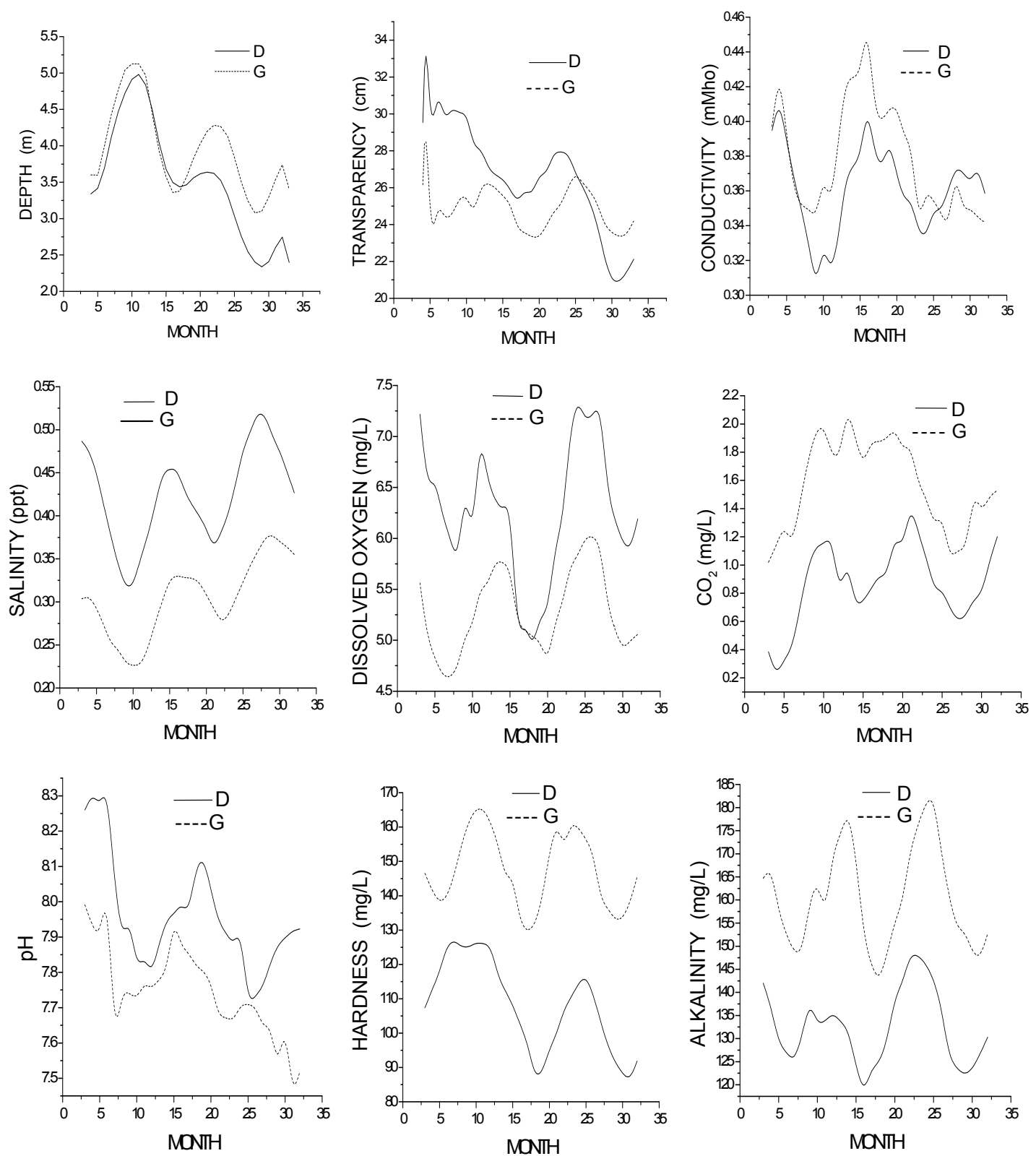

Figure 1. Time plot of monthly observed data of physico-chemical parameters of Gopalnagar (G) and Dumar (D) baur.

the water quality parameters in both the baurs. Although the pattern of variation was almost similar, there was wide difference in the level of these parameters between the two baurs except depth, $\mathrm{pH}$ and conductivity of water (Figure 1). Transparency of water also differed widely between the two baurs for the first year of observation; thereafter showed similarity between the two baurs. Depth of water significantly varied between the stations through out the experimental periods, while transparency, free $\mathrm{CO}_{2}$ and surface temperature of water showed significant variation between the stations for most part of the studies (Table 1). Depth decreased alarmingly during summer months and a trend of gradual decrease in depth was observed in both the baurs during the three year period of study. The Gopalnagar baur showed continuous decrease of depth from 2004 to 2006, while Dumar baur showed a sharp decrease of depth from 2004 to 2005, but did not show a marked decrease of depth thereafter. Transparency of water also showed a trend of gradual decrease in both the baurs. Salinity of water sharply decreased during monsoon and increased during summer. The highest value of salinity recorded in summer between 2005 and 2006 was higher than the summer value recorded between 2004 and 2005. Overall salinity, pH and dissolved oxygen levels were lower in Gopalnagar baur than Dumar baur, the later showing lower level of 
Table 1. F-ratio and critical difference (CD) value obtained from variance analysis of the physico-chemical parameters are given below. Bold face F-ratio indicates statistically significant variation between stations.

\begin{tabular}{|c|c|c|c|c|c|c|c|}
\hline \multirow{2}{*}{ Parameters } & \multirow{2}{*}{$\begin{array}{c}\text { Statistical } \\
\text { values }\end{array}$} & \multicolumn{3}{|c|}{ Gopalnagar baur } & \multicolumn{3}{|c|}{ Dumar baur } \\
\hline & & 2004 & 2005 & 2006 & 2004 & 2005 & 2006 \\
\hline \multirow{2}{*}{ Conductivity. } & F ratio & 2.05 & 3.86 & 4.26 & 2.38 & 20.28 & 0.48 \\
\hline & $\mathrm{CD}$ & 4.31 & 3.91 & 4.67 & 5.48 & 2.01 & 1.04 \\
\hline \multirow{2}{*}{ Depth } & $F$ ratio & 142.78 & 263.64 & 184.24 & 14.15 & 22.83 & 83.73 \\
\hline & $\mathrm{CD}$ & 3.68 & 4.96 & 10.86 & 17.78 & 9.54 & 7.01 \\
\hline \multirow{2}{*}{ DO } & $F$ ratio & 9.34 & 4.28 & 1.20 & 46.05 & 4.53 & 140.35 \\
\hline & $\mathrm{CD}$ & 6.59 & 5.96 & 9.54 & 3.13 & 9.01 & 1.42 \\
\hline \multirow{2}{*}{$\mathrm{pH}$} & $F$ ratio & 10.94 & 6.25 & 13.31 & 14.12 & 2.40 & 4.18 \\
\hline & $\mathrm{CD}$ & 1.39 & 1.47 & 0.65 & 2.53 & 0.77 & 1.03 \\
\hline \multirow{2}{*}{ Salinity } & F ratio & 0.27 & 34.44 & 4.37 & 0.13 & 1.44 & 1.83 \\
\hline & $\mathrm{CD}$ & 3.84 & 2.24 & 2.07 & 3.59 & 1.66 & 2.51 \\
\hline \multirow{2}{*}{ Water temperature } & F ratio & 7.84 & 0.59 & 13.35 & 15.63 & 35.06 & 44.37 \\
\hline & $\mathrm{CD}$ & 1.43 & 1.03 & .077 & 1.83 & 0.29 & 1.44 \\
\hline \multirow{2}{*}{ Transparency } & F ratio & 6.78 & 6.12 & 7.18 & 294.93 & 265.56 & 202.21 \\
\hline & $\mathrm{CD}$ & 3.68 & 2.26 & 1.82 & 2.73 & 1.67 & 2.51 \\
\hline \multirow{2}{*}{ Hardness } & F ratio & 15.91 & 3.63 & 22.94 & 30.76 & 138.64 & 0.13 \\
\hline & $\mathrm{CD}$ & 1.32 & 4.49 & 1.72 & 1.76 & 1.36 & 1.96 \\
\hline \multirow{2}{*}{ Alkalinity } & F ratio & 14.98 & 19.30 & 1.50 & 1.77 & 9.82 & 7.11 \\
\hline & $\mathrm{CD}$ & 2.43 & 2.67 & 2.83 & 2.93 & 3.81 & 1.54 \\
\hline \multirow{2}{*}{ Free $\mathrm{CO}_{2}$} & F ratio & 14.45 & 25.31 & 1.58 & 66.67 & 11.16 & 34.87 \\
\hline & $\mathrm{CD}$ & 7.19 & 3.43 & 29.85 & 6.01 & 9.74 & 6.35 \\
\hline
\end{tabular}

Table 2. Average annual diversity indices determined for three different stations of Gopalnagar and Dumar baur.

\begin{tabular}{cccccc}
\hline Year & Index & $\begin{array}{c}\text { Station } 1 \\
\pm \text { SD }\end{array}$ & $\begin{array}{c}\text { Station } 2 \\
\pm \text { SD }\end{array}$ & $\begin{array}{c}\text { Station } 3 \\
\pm \text { SD }\end{array}$ & $\begin{array}{c}\text { Overall mean } \\
\pm \text { SD }\end{array}$ \\
\hline $\begin{array}{c}\text { Gopalnagar baor } \\
2004\end{array}$ & SWI & $3.88 \pm 0.31$ & $3.81 \pm 0.55$ & $3.86 \pm 0.35$ & $3.85 \pm 0.35$ \\
& EI & $0.90 \pm 0.04$ & $0.87 \pm 0.09$ & $0.89 \pm 0.06$ & $0.89 \pm 0.05$ \\
2005 & ID & $0.08 \pm 0.00$ & $0.10 \pm 0.04$ & $0.08 \pm 0.02$ & $0.09 \pm 0.03$ \\
& SWI & $3.88 \pm 0.19$ & $4.02 \pm 0.22$ & $3.94 \pm 0.26$ & $3.95 \pm 0.16$ \\
& EI & $0.92 \pm 0.03$ & $0.93 \pm 0.04$ & $0.92 \pm 0.02$ & $0.92 \pm 0.02$ \\
2006 & ID & $0.08 \pm 0.01$ & $0.08 \pm 0.02$ & $0.08 \pm 0.02$ & $0.08 \pm 0.01$ \\
& SWI & $3.99 \pm 0.18$ & $3.91 \pm 0.21$ & $3.95 \pm 0.19$ & $3.95 \pm 0.12$ \\
& EI & $0.94 \pm 0.03$ & $0.94 \pm 0.02$ & $0.94 \pm 0.02$ & $0.94 \pm 0.01$ \\
2004 & ID & $0.08 \pm 0.02$ & $0.08 \pm 0.01$ & $0.07 \pm 0.01$ & $0.08 \pm 0.01$ \\
& & & & $3.61 \pm 0.24$ \\
& SWI & $3.52 \pm 0.27$ & $3.69 \pm 0.35$ & $3.63 \pm 0.32$ & $0.85 \pm 0.04$ \\
& EI & $0.84 \pm 0.06$ & $0.87 \pm 0.05$ & $0.86 \pm 0.05$ & $0.12 \pm 0.02$ \\
& ID & $0.13 \pm 0.04$ & $0.11 \pm 0.03$ & $0.11 \pm 0.03$ & $3.72 \pm 0.24$ \\
& SWI & $3.66 \pm 0.26$ & $3.72 \pm 0.28$ & $3.77 \pm 0.33$ & $0.89 \pm 0.03$ \\
& EI & $0.88 \pm 0.05$ & $0.90 \pm 0.04$ & $0.90 \pm 0.05$ & $0.1 \pm 0.02$ \\
& ID & $0.10 \pm 0.02$ & $0.10 \pm 0.02$ & $0.10 \pm 0.03$ & $3.84 \pm 0.12$ \\
& SWI & $3.84 \pm 0.2$ & $3.86 \pm 0.18$ & $3.83 \pm 0.18$ & $0.91 \pm 0.02$ \\
& EI & $0.91 \pm 0.03$ & $0.91 \pm 0.03$ & $0.90 \pm 0.04$ & $0.09 \pm 0.01$ \\
\hline
\end{tabular}

$\overline{\mathrm{SWI}}=$ Shannon-Weaver index; EI $=$ Evenness index; ID = Index of dominance

alkalinity, hardness and free carbon dioxide of water.

Mean annual values of Shannon-Weaver index, evenness index and index of dominance of fish fauna (Table 1) did not show any significant variation between the sampling stations of the two baurs (Table 3). Multiplicative decomposition method showed a gradual increase of Shannon-Weaver index and evenness index and a decrease of the index of dominance (ID) during the study period (Figure 2). Both S-W index and evenness index increased sharply during October-November, while index of dominance decreased during this period. While correlating the physico-chemical parameters of water with the diversity indices, it was observed that in both Gopalnagar and Dumar baur the Shannon-Weaver index was positively correlated with depth and negatively correlated with conductivity of water (Figures 3 and 4). In 

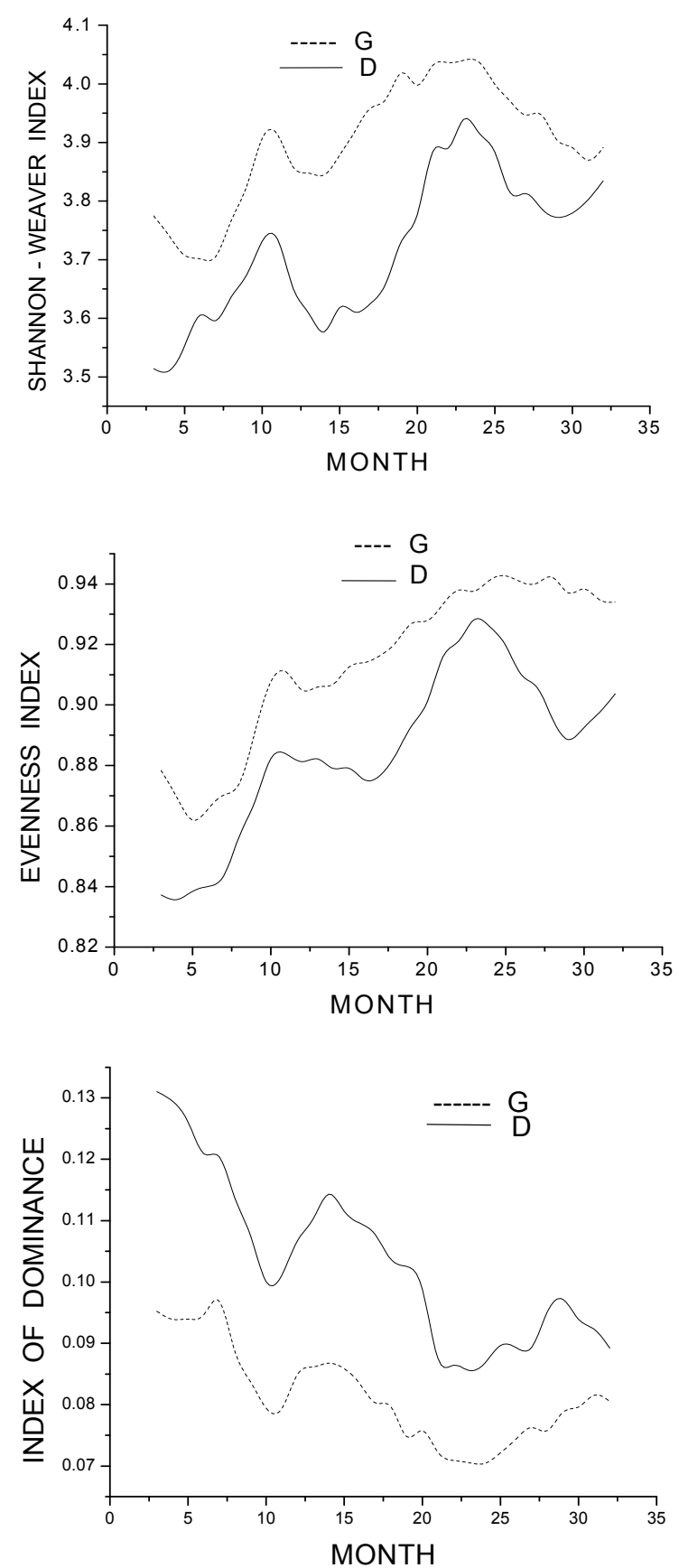

Figure 2. Time plot of monthly observed data of the diversity indices of fish fauna of Gopalnagar (G) and Dumar (D) baur.

Dumar baur Shannon-Weaver index was further positively correlated with free $\mathrm{CO}_{2}$ of water and negatively correlated with salinity of water (Figure 4).

\section{Discussions}

Conspicuous seasonal variation of the physico-chemical parameters of the two baurs reflected well defined dry and rainy seasons in the study area. Grand mean of each parameter, obtained form the MANOVA table, indicated that the physico-chemical parameters of the two baurs were suitable for fisheries purpose for the period of study undertaken. But a few parameters, such as depth and salinity, indicated a trend that could be alarming for the ecological sustainability of the baurs. A few studies on habitat structure and fish assemblages in lakes indicated that physico-chemical parameters could influence fish community structure of a lake $[15,16]$. But it was difficult to identify the key parameters that influenced the fish community structure most. Kar et al. [17] found dissolved oxygen of water to influence fish yield in the floodplain lakes of Assam, while Vono and Barbosa [16] observed abundance of macrophyte to influence total fish abundance in natural lakes. On the other hand, Deka et al. [18] observed that depletion of fish in wetlands was affected most by a cluster of variables consisting of siltation, anthropogenic activity, encroachment, flood effect, mesh size of net, indiscriminate catch and fishing rules. The results of the present study revealed that trend cycle, obtained by smoothing of the data series after reduction of random variation by multiplicative decomposition technique, was a strong tool to predict long term effect of the water quality parameters in baurs. Thus the declining trend of depth in the baurs under study gained most significance and need for an effective control program to maintain optimum depth for sustainable fisheries in the baurs was felt necessary. Siltation from the river meanders, discharge of organic debris from human settlements around the lakes and run-offs from agricultural fields primarily resulted in reduction of depth of many floodplain lakes in India [2,7,8]. Siltation and anthropogenic activities were found as the major cause of depletion of fish stocks in floodplain lakes of Assam [18]. Present results indicated that worst situation prevailed in the baurs of Bongaon subdivision (W.B., India) during summer months, when extreme reduction of depth resulted in increase of salinity, free $\mathrm{CO}_{2}$ and hardness of water and decrease of dissolved oxygen, $\mathrm{pH}$ and transparency of water rendering a reduction in fish diversity. Apart from continuous removal of water for irrigation purpose and heavy infestation of weeds, which primarily caused reduction of depth, wide spread use of the baurs for jute retting was found to cause a large scale degradation of the water quality parameters particularly during summer months in these baurs [9]. Such ecological degradation was reflected in poor catch of fish [5] and decrease of diversity index during summer months from these baurs. Since salinity of water was inversely related with the depth of water a negative relation between the salinity of water and Shannon-Weaver index (SWI) was exhibited in the baur. A general trend of decrease in depth and an increase in salinity was considered to produce serious impact on sustainability of these floodplain lakes.

The present study indicated a conspicuous seasonal fluctuation of Shannon-Weaver index and evenness in- 
Table 3. F ratio and critical difference (CD) value obtained from variance analysis of various diversity indices of finfish from Gopalnagar and Dumar baur.

\begin{tabular}{|c|c|c|c|c|c|c|c|}
\hline \multirow{2}{*}{ Parameters } & \multirow{2}{*}{$\begin{array}{l}\text { Statistical } \\
\text { values }\end{array}$} & \multicolumn{3}{|c|}{ Gopalnagar baur } & \multicolumn{3}{|c|}{ Dumar baur } \\
\hline & & 2004 & 2005 & 2006 & 2004 & 2005 & 2006 \\
\hline \multirow{2}{*}{ Shannon-Weaver index } & $\mathrm{F}$ ratio & 0.23 & 0.72 & 0.99 & 1.15 & 1.65 & 2.01 \\
\hline & CD & 6.47 & 5.70 & 4.23 & 3.56 & 4.99 & 5.23 \\
\hline \multirow{2}{*}{$\begin{array}{l}\text { Evenness } \\
\text { index }\end{array}$} & F ratio & 1.58 & 0.35 & 0.04 & 1.66 & 0.53 & 0.43 \\
\hline & $\mathrm{CD}$ & 4.08 & 2.66 & 2.37 & 5.17 & 4.73 & 3.15 \\
\hline \multirow{2}{*}{ Index of dominance } & F ratio & 1.99 & 0.26 & 0.25 & 1.18 & 0.05 & 0.68 \\
\hline & $\mathrm{CD}$ & 19.53 & 16.48 & 15.02 & 16.99 & 19.30 & 15.21 \\
\hline
\end{tabular}
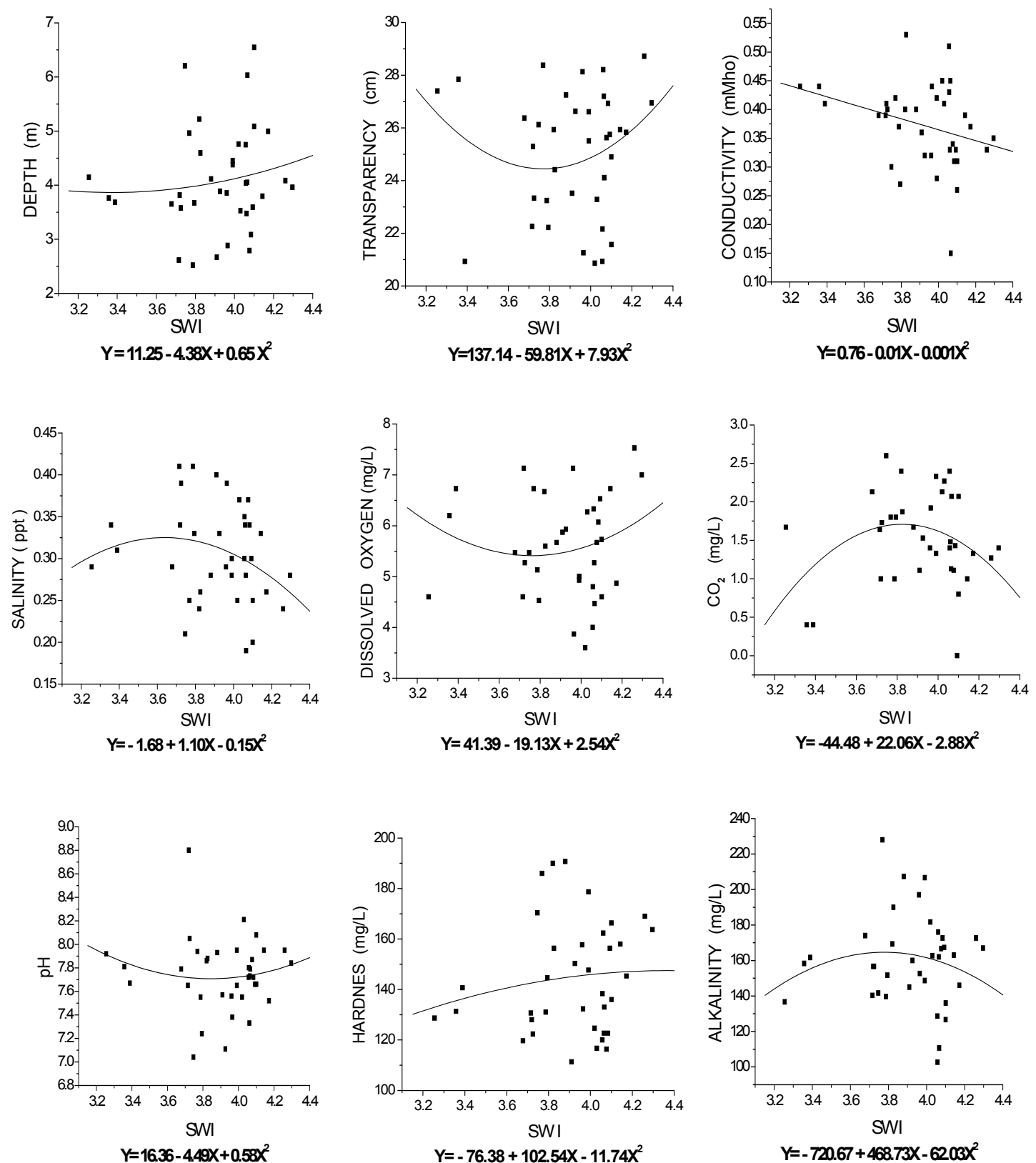

Figure 3. Quadratic relationship between physico-chemical parameters and Shannon-Weaver index (SWI) of fish fauna in Gopalnagar baur. 


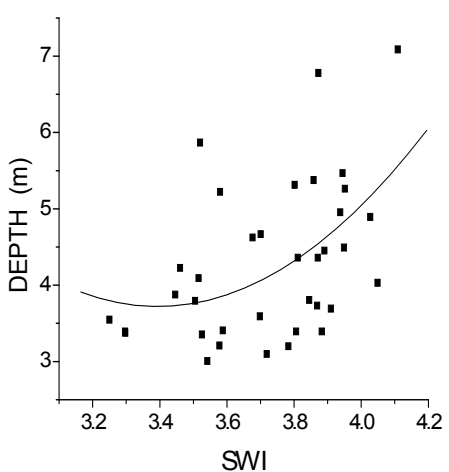

$Y=45.15-24.14 X+3.59 X^{2}$
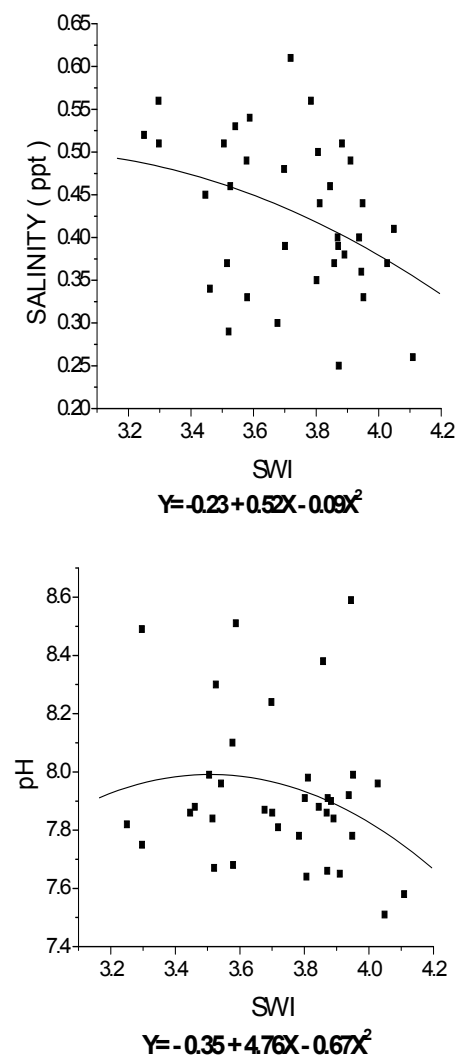

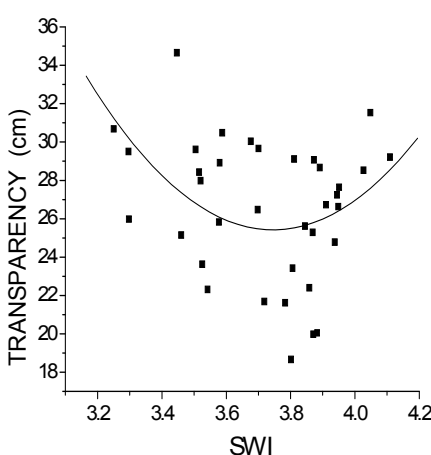

$Y=358.05-177.60 X+23.70 X^{2}$
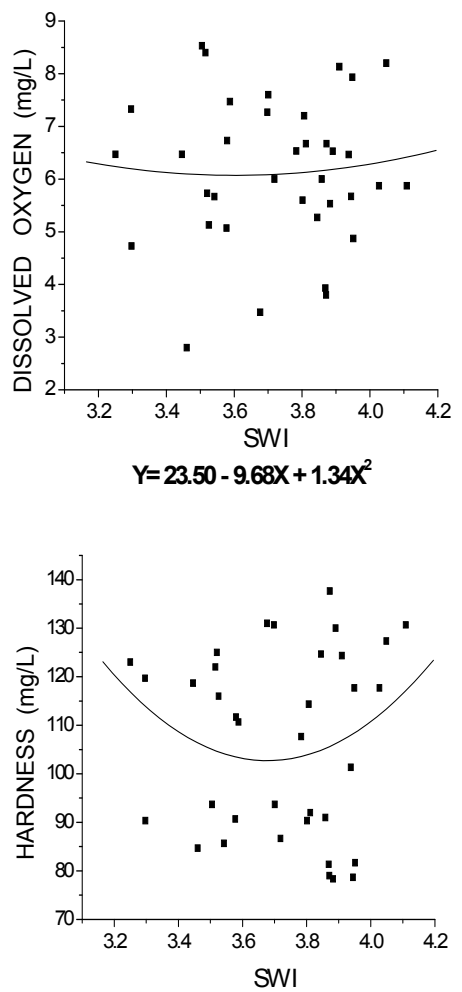

$Y=1150.26-526.68 X+773.12 X^{2}$

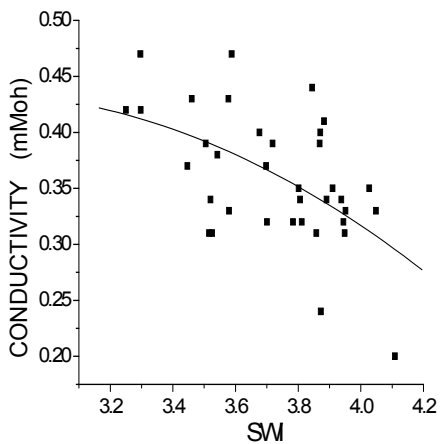

$Y=1.12+0.41 X-0.7 X^{2}$
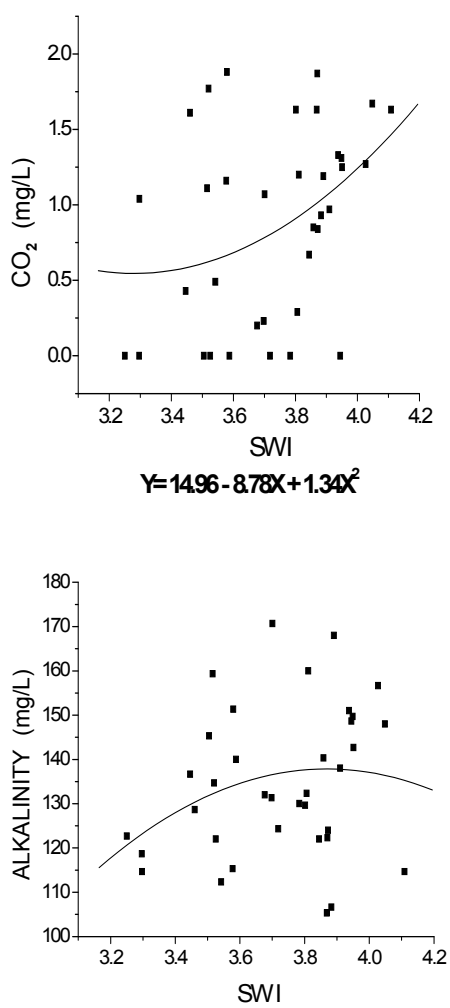

$Y=-533.94+347.25 X-44.87 X^{2}$

Figure 4. Quadratic relationship between physico-chemical parameters and Shannon-Weaver index (SWI) of fish fauna in Dumar baur.

dex, post monsoon period (Sept-Oct) showing the peak. Number of species and the total number of individuals of all species harvested in each sample from these two baurs fluctuated between the seasons [5]. Since both the baurs were connected with a river, many species of fish migrated from the river to breed in the baur during monsoon (July-Aug). Species number thus increased during Sept-Oct rendering an increase in the Shannon-Weaver index. However, this study indicated that there was a trend of increase in the Shannon-Weaver index and evenness index in both the baurs. This was due to grad- ual reduction in number of individuals of the dominant species captured in both the baurs [5], resulting in a gradual reduction of index of dominance.

Despite clear changes in species composition Carol et al. [6] found no significant effect of water quality on overall fish richness or Shannon's diversity in some Spanish reservoirs. These reservoirs had low richness assemblages and these authors suggested that in such case species composition was a better indicator of cultural eutrophication of reservoirs than fish diversity. The present study however, indicated that quadratic regres- 
sion analysis was an effective tool to establish relationship between water quality parameters and the finfish diversity indices in the floodplain lakes. The results of the quadratic regression analysis indicated that apart from depth and salinity, conductivity and free $\mathrm{CO}_{2}$ of water also produced significant effect on ShannonWeaver index and fluctuation of these physico-chemical parameters should be taken into consideration while predicting future effects on finfish diversity of the floodplain lakes under study. The quadratic relationship was also worked out between the physico-chemical parameters and the evenness index and dominance index (results not presented) and almost same picture was revealed. However, it was revealed that fluctuation of all three diversity indices should be considered while evaluating the trend of the diversity and designing policies on long term sustainability of the floodplain lakes.

\section{Acknowledgements}

Authors acknowledge the facilities of research provided by the Head, Department of Zoology, University of Kalyani and Fishermen Cooperative Society associated with Gopalnagar and Dumar baur.

\section{References}

[1] U. Bhaumik, B. C. Jha, K. Mitra, and G. K. Vinci "Fish yield optimization in beels: Some case studies from West Bengal," Bulletin of Central Inland Fisheries Research Institute, Barrackpore, No. 125, pp. 43-54. 2003.

[2] R. A. Khan, "The ecology and faunal diversity of two floodplain ox-bow lakes of south eastern West Bengal," Records of the Zoological Survey of India, No. 195, pp. $1-57,2002$.

[3] Anonymous, "Annual report 2004-2005," Department of Fisheries, Aquaculture, Aquatic Resources and Fishing Harbours, Government of West Bengal, pp. 25-27, 2006.

[4] S. R. Das and N. C. Nandi, "Oxbow lake environment and management of Ichhamati river basin, West Bengal," Journal of Environment and Sociobiology, Vol. 1, pp. 81-90, 2004.

[5] D. K. Mondal and A. Kaviraj, "Distribution of fish assemblages in two floodplain lakes of North 24 - Parganas in West Bengal, India," Journal of Fisheries and Aquatic Science, Vol. 4, pp. 12-21, 2009.

[6] J. Carol, L. Benejam, C. Alcaraj, A. Vila-Gispert, L.
Zamora, E. Navarro, J. Armengol, and E. Garcia-Berthou, "The effects of limnological features on fish assemblages of 14 Spanish reservoirs," Ecology of Freshwater Fish , Vol. 15, pp. 66-77, 2006.

[7] M. M. Goswami, T. K. Deka, P. K. Singha, P. K. Sharma, and M. Kakati, "Studies of some wetlands of Assam with reference to the eutrophication stresses," Journal of the Inland Fisheries Society of India, Vol. 31, pp. 39-43, 1999.

[8] V. V. Sugunan and B. K. Bhattacharjya, "Ecology and fisheries of beels in Assam," Bulletin of Central Inland Fisheries Research Institute, No. 104, pp. 1-65, 2000.

[9] D. K. Mondal and A. Kaviraj, "Ecotoxicological effects of jute retting on the survival of two freshwater fish and two invertebrates," Ecotoxicology, Vol. 17, pp. 207-211, 2008.

[10] APHA (American Public Heath Association), "Standard methods for examination of water and waste water," American Public Health Association, American Water Works Association and Water Pollution Control Federation, Washington, DC, USA, 1995.

[11] C. E. Shannon and W. Weaver, "The mathematical theory of communication," Urbana, University of Illinois, pp. 117-125, 1963.

[12] E. C. Pielou, "The measurement of diversity in different types of biological collections," Journal of Theoretical Biology, Vol. 13, pp. 131-144, 1966.

[13] E. W. Simpson, "Measurement of diversity," Nature, Vol. 163, pp. 688, 1949.

[14] S. Makridakis, S. C. Wheelright, and R. J. Hyndman, "Forecasting methods and applications," 3rd edition, John Wiley \& Sons, Singapore, 2003.

[15] B. J. Benson and J. Magnuson, "Spatial heterogeneity of littoral fish assemblages in lakes: Relation to species diversity and habitat structure," Canadian Journal of Fisheries and Aquatic Science, Vol. 49, pp. 1493-1500, 1992.

[16] V. Vono and F. A. R. Barbosa, "Habitat and littoral zone fish community structure of two natural lakes in southeast Brazil," Environmental Biology of Fishes, Vol. 61, pp. 371-379, 2001.

[17] D. Kar, A. V. Nagarthana, T. V. Ramachandra, and S. C. Dey, "Fish diversity and conservation aspects in an aquatic ecosystem in northeastern India," Zoos'Print Journal, Vol. 21, pp. 2308-2315, 2006.

[18] T. K. Deka, M. M. Goswami, and M. Kakati, "Causes of fish depletion - a factor analysis approach," NAGA, World Fish Centre Newsletter, Vol. 28, pp. 37-42, 2005. 